\title{
Using Landsat 8 imagery in detecting cork oak (Quercus suber L.) woodlands: a case study in Calabria (Italy)
}

\author{
Giuseppe Modica, Francesco Solano, Angelo Merlino, Salvatore Di Fazio, \\ Francesco Barreca, Luigi Laudari, Carmelo Riccardo Fichera \\ Department of Agriculture, Mediterranean University of Reggio Calabria, Italy
}

\begin{abstract}
In the Mediterranean basin, cork oak (Quercus suber L.) woodlands are characteristic and widespread forestry ecosystems. Though presenting significant economic potential as a renewable resource, they are not adequately valorised, in spite of a growing market demand for cork and cork-based products, which are appreciated, today, for their use in sustainable building. In this respect, cork meets the needs of the building industry in responding to the growing demand for quality products, which are eco- and energy-friendly and hygienically safe. Moreover, European cultural and biodiversity value has been attributed to cork oak woodlands and their most significant examples have been included in the Natura 2000 framework. So far, in some countries like Italy, the territorial distribution and characterisation of cork oak woodlands have not been adequately investigated. This study provides a method for mapping the actual presence of cork oak woodlands and for
\end{abstract}

Correspondence: Giuseppe Modica, Department of Agriculture, Mediterranean University of Reggio Calabria, Loc. Feo di Vito I, 89122 Reggio Calabria, Italy.

Tel.: +39.0965.1694261. E-mail: giuseppe.modica@unirc.it

Key words: Accuracy assessment; Calabria (Italy); cork oak woodlands; Landsat 8 imagery; remote sensing; spectral separability.

Funding: this research was carried out within the research project SUBERWALL funded in the framework of the Rural Development Programme (RDP) 2007-2013 of the Calabria Region (Measure 124, grant n. 94752170756). The research was also supported by projects PONa3_00016-RI-SAF@MED (Research Infrastructure for Sustainable Agriculture and Food in Mediterranean area), and PON03PE_00090_2 in the framework of National Operational Programme (NOP) for Research and Competitiveness 20072013 of the Italian Ministry of Education, University and Research (MIUR) and Ministry of Economic Development (MiSE), and co-funded by the European Regional Development Fund (ERDF).

Conflict of interest: the authors declare no potential conflict of interest.

Received for publication: 14 June 2016.

Accepted for publication: 17 September 2016.

(C) Copyright G. Modica et al., 2016

Licensee PAGEPress, Italy

Journal of Agricultural Engineering 2016; XLVII:571

doi:10.4081/jae.2016.571

This article is distributed under the terms of the Creative Commons Attribution Noncommercial License (by-nc 4.0) which permits any noncommercial use, distribution, and reproduction in any medium, provided the original author(s) and source are credited. assessing their potential distribution. Special attention was given to the characterisation of cork oak spectral signature. To this end, Landsat 8 satellite images, digital photointerpretation and in situ surveys were implemented. The work carried out allows assessing the effectiveness of GIS and remote sensing techniques coupled with ancillary data and tools, and their applicability for the development of a comprehensive mapping and monitoring system of cork oak woodlands in Mediterranean ecosystems. Such techniques are vital to develop a detailed management strategy and to assist restoration activities and the economic assessment of semi-natural habitats. A case study, carried out in two different locations in Calabria (Italy), is provided.

\section{Introduction}

Cork oak (Quercus suber L.) woodlands define a characteristic Mediterranean landscape type whose ecological and economic value is largely recognised. Cork oak is widespread in the western Mediterranean Basin (Figure 1) covering an area roughly estimated at 2.7 million ha in 2006 (WWF MedP0, 2006), 2.5 million ha in 2009 (Aronson et al., 2009; Catry et al., 2012a, 2012b) and 2.2 million ha in 2013 (FA0, 2013), mainly in seven countries: Portugal, Spain, Algeria, Morocco, Tunisia, Italy and France. Cork oak forests are semi-natural ecosystems that, today, provide significant income for more than 100,000 people and support one of the highest levels of biodiversity among forest habitats (MedP0, 2006; FA0, 2013). Cork oak ecosystems are recognised as unique habitats worthy of conservation at European level and consequently included in Annex I of the so-called Habitats Directive of the Council of Europe (European Commission, 1992). As a matter of fact, in Mediterranean areas these ecosystems play a significant role in the implementation of ecological networks aiming at the reduction of landscape fragmentation in the framework of environmental conservation strategies (Fichera et al., 2015).

Cork is the main product obtained from Q suber L.; it is a renewable and biodegradable material, which has been mainly extracted so far to obtain bottle stoppers for the wine industry. As to cork production, inconsistent data can be found in literature: recently, Bugalho et al. (2011) have reported an annual production of approximately $300,000 \mathrm{t}$ in the Mediterranean Basin, 70\% of which transformed into bottle stoppers; APCOR (2015), citing FAO statistics, has reported a production of 201,000 t. Globally, cork is the sixth most important non-timber forest product (Bugalho et al., 2011; FA0, 2013), the second in the western Mediterranean, even though, recently, a world market devaluation of cork has been recorded (Aronson et al., 2009). In recent years, materials other than natural cork have been increasingly used for the production of bottle stoppers. In contrast, a new demand for cork-based materials and components has emerged from the building industry, which is currently searching for healthy and sustainable technical solutions: cork has therefore been used for producing glue-free walling blocks made of compressed cork granules; flooring and roofing sheets; 
wall coating sheets; water resistant and insulating (thermal, acoustic) panels. Furniture and interior design are also giving further and interesting contribution to the valorisation of cork, even recognising the public's appreciation for its aesthetic qualities.

On the one hand, this new demand for cork supply requires new approaches to the management of cork oak woodlands in order to explore their production potential and make their exploitation fully compatible with their important environmental and ecological function. On the other hand, since several factors (overharvesting, overgrazing, wildfires, etc.) have contributed and are still contributing to the degradation of cork oak forests (FA0, 2013), the restoration of the degraded sites should represent a major target for the conservation of biological diversity in the Mediterranean area (Modica et al., 2015). In this regards, it is important to notice how in the Mediterranean area widespread agricultural lands, evergreen woodlands and maquis shrublands are the result of anthropogenic disturbances that deeply modified the landscapes especially in the last decades (e.g., Modica et al., 2012).

To that purpose, Modica et al. (2015) proposed a forest degradation index for identifying a threshold value below which a forest can be termed as degraded, applied and validated also in cork oak forest types. It is clear that precise and updated knowledge of the territorial distribution, consistency and state of cork oak woodlands is needed for both production-enhancement and nature-conservation purposes.

This work is intended to offer a contribution towards this objective by making reference to Italy and, in particular, to the Calabria region, where cork oak has significant importance.

As highlighted before, in Italy, and in a few other Mediterranean countries, cork oak distribution is not precisely known. According to Vessella and Schirone (2013), in Italy, cork oak can be found along the peninsular Tyrrhenian coast (from Liguria to Calabria), in the islands of Sicily and Sardinia and in small nuclei along the Apulian coast. Figure 1 shows two of the most referenced maps of cork oak distribution. Rossi et al. (2009) detected cork oak woodlands by means of satellite images (Ikonos and Landsat Thematic Mapper 5) in sample areas of the Latium Region (Italy). Recently, an ecological-niche modelling approach has been proposed to map the potential distribution of cork oak in Italy (Vessella and Schirone, 2013).

Detailed mapping of forest types based on the analysis of high resolution remotely sensed imagery can still be considered a challenging work due to the confusion caused by forest landscape heterogeneity (Rogan and Miller, 2006) that, especially in the Mediterranean ecosystems, can lead to a misidentification of forest types.

Regarding the Landsat family products, they were applied in determining land cover (LC) of oak forest types in few researches (Wang et al., 2007; Zhu and Liu, 2014). On the other hand, Landsat thematic mapper imagery was applied to estimate the canopy cover (Carreiras et al., 2006) and the canopy density (Godinho et al., 2014) in cork and holm oak woodlands. A comprehensive description of the Landsat family can be retrieved at the following website, http://andsat.usgs.gov/ index.php (accessed: 20 May, 2016).

This study provides a method for mapping the actual consistence of cork oak woodlands in the Calabria region and for assessing their potential territorial distribution. The proposed methodology was applied to Calabria (South of Italy), where cork oak woodlands are widespread and mixed with non-native species. Moreover, so far, their territorial distribution and characterisation has not been adequately investigated taking into account the main features determining their productivity. Different methods have been used but they have not produced a comprehensive picture of the species and its habitats. The first stage of the study focuses on the characterisation of cork oak spectral signature compared to other potentially similar land uses.

\section{Materials and methods}

\section{Study areas}

The study was carried out in two sample areas in Calabria: i) Mount Scrisi (Scr), which is part of Reggio Calabria province and extends over $42.6 \mathrm{~km}^{2}$ at $400 \div 500 \mathrm{~m}$ a.s.l., on the Tyrrhenian side of the Aspromonte massif; ii) Angitola (Ang), which is part of Vibo Valentia province and extends over $49.2 \mathrm{~km}^{2}$ at $100 \div 150 \mathrm{~m}$ a.s.l. with a predominantly northern aspect (Figure 2).

Referring to the main goal of this paper, the forest cover of the Scr study area is characterised by a thermo-mesophilous woodland dominated by cork oak (Q. suber $\mathrm{L}$.) with a meso-Mediterranean sub-humid bioclimatic type. The mean annual rainfall ranges between 700 and $1000 \mathrm{~mm}$, while the mean annual temperature ranges from 14 to $16^{\circ} \mathrm{C}$. From the phytosociological point of view, it refers to a variant of the Helleboro-Quercetum suberis (Signorello, 1984) with Cytisus villosus Pourret and a shrub layer of Erica arborea L. and Arbutus unedo L.

The Ang study area is characterised by a mesophilous woodland dominated by cork oak (Q. suber L.), sometimes mixed with holm oak (Quercus ilex L.) and Quercus virgiliana Ten. From the phytosociological point of view, it refers to the Helleboro-Quercetum suberis (Signorello, 1984) and is related to humid meso-Mediterranean bioclimatic conditions (an average annual rainfall over $1000 \mathrm{~mm}$ and annual mean temperatures ranging from 14 to $16^{\circ} \mathrm{C}$ ). These two study areas were chosen mainly because of the need of a continuous canopy cover

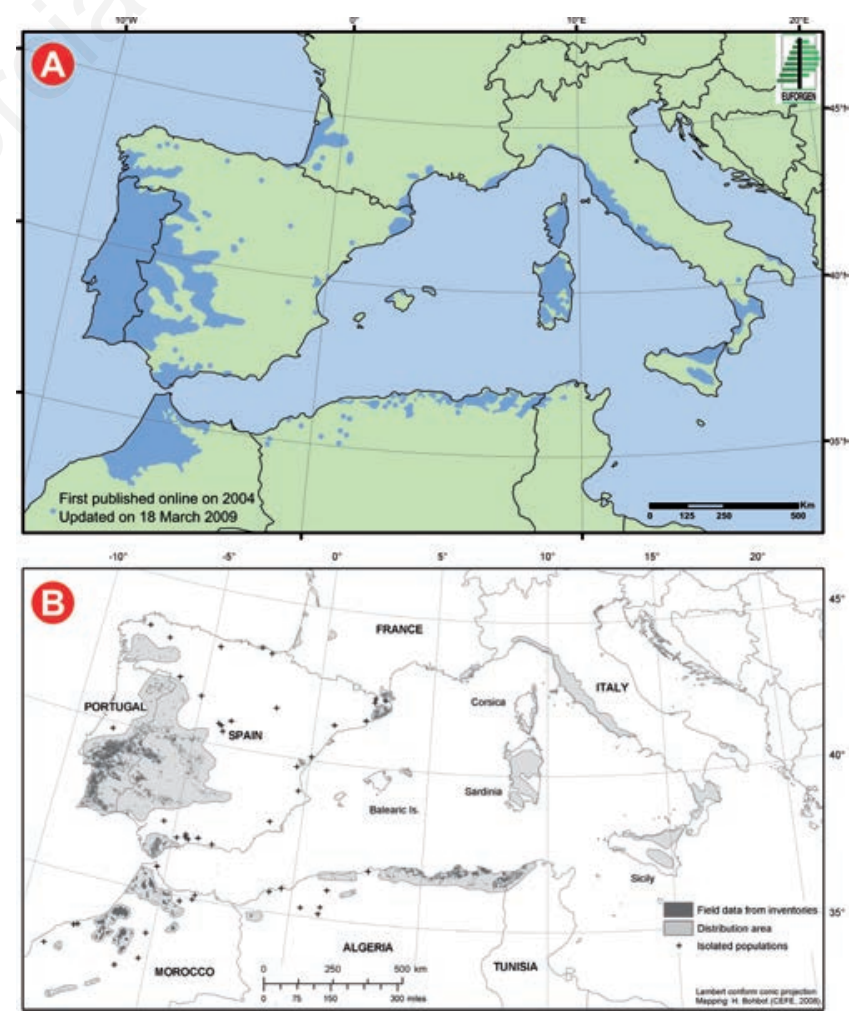

Figure 1. Distribution maps of cork oak (Quercus suber L.) according to: A) EUFORGEN 2009 (www.euforgen.org); and B) Pausas, Pereira \& Aronson (2009) [Reproduced from Aronson et al. (2009); Copyright (C) 2009 Island Press. Reproduced by permission of Island Press, Washington, DC]. 
sufficient to well characterise cork oak's spectral signature as well as considering their different bioclimatic conditions. Both sites were geolocated on the basis of available information (personal information from experts, bibliographic sources, etc.), and of a series of preliminary in situ surveys. Moreover, the Scr study area was chosen also considering the recognised natural value of its cork oak woodlands that, in 1995, motivated its designation as a site of community interest in the framework of the Habitats Directive. Figure 2 shows a first picture of the territorial distribution of cork oak woodlands of at least 5 ha.

\section{Satellite data}

\section{Landsat 8 archives}

Launched in February 2013 (data available from May 2013), Landsat 8 satellite is the latest member of the Landsat data continuity mission, which began in 1972. Landsat 8 is equipped with two sensors: the operational land imager (OLI) and the thermal infrared sensor (TIRS). They provide data at a spatial resolution of 30 meters for visible, near infrared (NIR), and short-wave infrared bands, and of 15 meters for panchromatic bands (Table 1). All bands are collected at 12-bit, and that, if compared with Landsat 7 enhanced thematic mapper plus $(\mathrm{ETM}+)$ data (8-bit), can significantly improve the detection of temporal variation and spatial diversity of vegetation. As highlighted by Roy et al. (2014), the OLI and TIRS are push-broom sensors, which, thanks to the on-board GPS, allow obtaining images with an improved geometric fidelity in comparison with the previous Landsat images. Moreover, compared to the ETM+, the new OLI sensor should be more sensitive to the surface reflectance variability and less influenced by atmospheric conditions (Ke et al., 2015).

As largely recognised by scholars, the Landsat program strength lies in its continuity (e.g., Fichera et al., 2011, 2012; Di Palma et al., 2016). Moreover, the Landsat OLI and ETM+ sensors have proven to be a reliable source of data for land use (LU)/LC monitoring for the following characteristics: a relatively high spatial resolution $(15 \div 30 \mathrm{~m})$; a wide swath (the approximate scene size is $170 \mathrm{~km}$ North-South by $183 \mathrm{~km}$ East-West); a frequent repeat cycle of 16 days that can be potentially increased combining the data of the two sensors, thus reaching a theoretical repeat cycle of 8 days. In the operational contexts, such a revisitation period is far to obtain, mainly due to cloud cover and to the fact that the data acquisition gives priority to scenes for the USA. Moreover, limitations of Landsat data also include the fixed acquisition schedule that makes difficult to acquire imagery, for a particular place at a par- ticular time especially if smoke or clouds occur frequently over the area of interest. This could be overcome using other satellite imagery, such as Sentinel-2, which every week offer an outlook over the planning period providing a Google Earth KML file with detailed information on the image segments.

\section{Data acquisition and pre-processing}

For both investigated study areas, all available cloud-free OLI imagery (path 188, row 33 of the Landsat worldwide reference system2, WRS-2) were obtained at level 1 terrain-corrected (L1T) with universal transverse Mercator (UTM) map projection, datum world geodetic system84 (WGS84). The Landsat $8 \mathrm{L1T}$ data processing includes radiometric calibration and geometric and precision corrections. Considering the specific aim of this work and the given geolocation uncertainty of less than $12 \mathrm{~m}$ of circular error for L1T data product (Irons et al., 2012), it was not necessary to improve the geographic location of the Landsat 8 imagery. Anyway, the geolocation of these images was visually checked through overlapping with the regional numerical topographic map (CTR, which stands for carta tecnica regionale) produced at 1:5000 nominal scale.

A total of 6 OLI images for years 2014 and 2015 (22 May, 23 June, 25
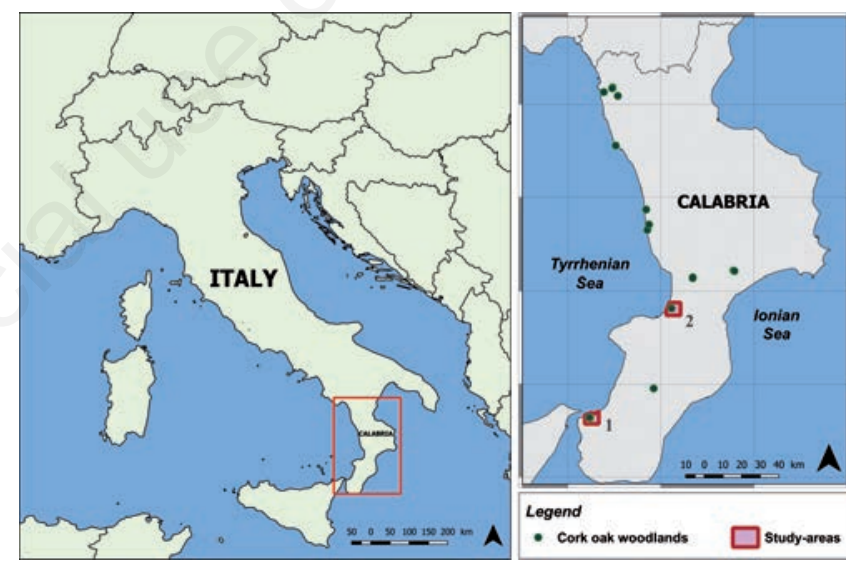

Figure 2. Geographical location of the two study-areas: 1 - Scrisi Mount (Scr); 2 - Angitola (Ang). Green-points in the map show the presence of Quercus suber $L$. woodlands extended at least 5 ha.

Table 1. Band comparison of Landsat 8 operational land imager and thermal infrared sensor with the Landsat 7 enhanced thematic mapper plus. Unless otherwise denoted, all bands have $30 \mathrm{~m}$ native resolution.

\begin{tabular}{|c|c|c|c|}
\hline $\begin{array}{l}\text { Landsat } 8 \text { (OLI and TIRS) } \\
\text { Band description }\end{array}$ & $\begin{array}{l}\text { Wavelength } \\
\qquad(\mu \mathrm{m})\end{array}$ & $\begin{array}{l}\text { Landsat } 7 \text { (ETM+) } \\
\text { Band description }\end{array}$ & Wavelength ( $\mu \mathrm{m})$ \\
\hline Band 1 - Coastal aerosol & $0.43-0.45$ & - & - \\
\hline Band 2 - Blue & $0.45-0.51$ & Band 1 - Blue & $0.45-0.52$ \\
\hline Band 3 - Green & $0.53-0.59$ & Band 2 - Green & $0.52-0.60$ \\
\hline Band 4 - Red & $0.64-0.67$ & Band 3 - Red & $0.63-0.69$ \\
\hline Band 5 - Near infrared & $0.85-0.88$ & Band 4 - Near infrared & $0.77-0.90$ \\
\hline Band 6 - Shortwave infrared & $1.57-1.65$ & Band 5 - Shortwave infrared & $1.55-1.75$ \\
\hline Band 7 - Shortwave infrared & $2.11-2.29$ & Band 7 - Shortwave infrared & $2.09-2.35$ \\
\hline Band 8 - Panchromatic (15 m) & $0.50-0.68$ & Band 8 - Panchromatic (15 m) & $0.52-0.90$ \\
\hline Band 9 - Cirrus & $1.36-1.38$ & - & - \\
\hline Band 10 - Thermal Infrared $(100 \mathrm{~m})$ & $10.60-11.19$ & Band 61 - Thermal Infrared (60 m) & 10.40-12.50 (high gain) \\
\hline Band 11 - Thermal Infrared (100 m) & $11.50-12.51$ & Band 62 - Thermal Infrared $(60 \mathrm{~m})$ & 10.40-12.50 (low gain) \\
\hline
\end{tabular}

OLI, operational land imager; TIRS, thermal infrared sensor; ETM+, enhanced thematic mapper plus. Source: http://landsat.usgs.gov/band_designations_landsat_satellites.php Accessed: 20 May 2016. 
July, 10 August, 26 August for year 2014; 23 April for year 2015) were downloaded from the United States Geological Service (USGS) EarthExplorer service (http://earthexplorer.usgs.gov accessed: 20 May, 2016). From the original 11 OLI-TIRS bands, only multispectral (MS) bands 1-7 were selected and sharpened with the panchromatic (Pan) band 8. Image pan-sharpening (or data fusion) algorithms were applied in order to increase the spatial resolution of the MS bands 1-7 (30 $\mathrm{m})$ using the higher spatial resolution Pan band (15 m), allowing for smaller LU/LC features detection. Currently, a number of algorithms are being proposed and implemented in software packages and several scholars have been investigating and comparing their performances in pan-sharpening different imagery. In this study, the hyperspherical colour space (HCS) resolution merge algorithm, recently proposed by Padwick et al. (2010), was used to sharpen the OLI images. HCS is a procedure originally designed for WorldView 2 sensor 8 band data but widely used in pan-sharpen MS data with at least three bands. The proposed HCS method has two modes: naïve and smart mode. The latter, which is similar to the smoothing filter-based intensity modulation technique (Liu, 2000), was implemented in the ERDAS Imagine suite. HCS was chosen because it generally preserves the original spectral contents of the image, as also demonstrated by Dahiya et al. for Ikonos imagery (2013), and allows obtaining a good spatial improvement of the original MS 1-7 bands. Boundaries in the pan-sharpened images were clearer and smoother than those on the former MS images. As suggested by Padwick et al. (2010), a 7×7 smoothing filter was applied while the sharpened output images were resampled by means of the nearest neighbour interpolation algorithm. Then, to better investigate smaller LU/LC features detection, a subset of the L8 sharpened output images was performed, for both the study areas.

The raw quantised calibrated pixel values of the original MS images (digital numbers, DNs) must be converted into top of atmosphere reflectance. Moreover, in order to improve the quality of qualitative and quantitative analyses, topographic correction is necessary for imagery obtained from optical or passive remote sensing and covering mountainous areas. All the pan-sharpened OLI images were atmospherically and topographically corrected to surface reflectance using all selected bands (1-7) by means of the ATCOR3 module for Erdas Imagine ${ }^{\circledR} 2015$. ATCOR belongs to the semi-empirical correction methods and provides a good compromise between general performance, computational simplicity, and physical-structural basis (Balthazar et al., 2012; Vanonckelen and Lhermitte, 2014). Atmospheric corrections implemented in ATCOR convert the original DNs into spectral radiance at sensor's aperture $\left(\mathrm{L}_{\lambda}\right)$ using the calibration parameters and gain and offset (or bias) values provided in imagery metadata. In formula (Eq. 1):

\section{$\mathrm{L}_{\lambda}=D N \cdot$ gain + offset $\left[\mathrm{W} \mathrm{m}^{-2} \mathrm{sr}^{-1} \mu \mathrm{m}^{-1}\right]$}

ATCOR algorithm is based on the MODTRAN atmospheric radiative transfer code and incorporates a compiled database containing the results of the radiative transfer calculations for a wide range of weather conditions and solar zenith and azimuth angles. In this study, a rural aerosol model for spring and summer atmospheric models was applied. As to the visibility, a distance of $15 \mathrm{~km}$ and $59 \mathrm{~km}$ was applied to the study area of Scr and Ang, respectively. Starting from L, surface reflectance values were obtained removing atmosphere disturbances.

The topographic correction in ATCOR3 is based on a modified Minnaert topographic correction using a set of empirical rules (Richter et al. 2009). ATCOR3 accounts for rugged terrain effects obtaining four terrain files (slope, aspect, sky view, and shadow cast) from a digital elevation model (DEM) (Richter, 1997; Richter, 1998). Since areas of low illumination are normally associated with steep slopes, an inadequate spatial resolution of reference DEM will strongly affect the topographic correction (Richter, 1998). To obtain a good compromise, it would be desirable to have a DEM with a spatial resolution of 0.25 times the pixel size of the corrected image or better (Goodenough et al., 1990; Richter, 1998; Richter, 2008). Therefore, in this study, a $2.5 \times 2.5 \mathrm{~m}$ DEM, obtained by interpolating the original contour lines and the elevation points of the numerical CTR (Figure 3), was used.

Finally, an anomaly detection (AD) process was carried out through the Spectral Analysis Workstation of ERDAS imagine. AD is the process of searching an input image to identify pixels that have a spectral signature that deviates markedly from most other pixel spectra in the image (the background spectra). The output of AD is an anomaly mask, depicting areas in the input image, that are markedly different from their surroundings that was used during classification as input information for unclassified pixels. In this study, the orthogonal subspace projection was chosen as detection method.

\section{Data processing and image classification}

As highlighted in the Introduction section, this study was focussed on the characterisation and separability of the spectral signatures of cork oak woodlands in different seasonal periods. Signature separability is a statistical measure of the spectral distance between two signatures. To this end, a group of land uses was defined obtaining their spectral signatures from a set of 55 ground control points (GCP) ground truths - collected by means of differential global navigation satellite system with accuracy $\pm 0.5 \mathrm{~m}$ (Table 2). As shown in Table 2,

Table 2. Ground control points - ground truths - collected in the two study-areas, Scrisi Mount and Angitola.

No. of GCP - ground truths
Scrisi Mount
(Scr) Angitola

\begin{tabular}{lcc} 
Urban settlements (Ur) & - & 3 \\
Roads (Ro) & 2 & 9 \\
\hline Crops (Cr) & 5 & 8 \\
Coniferous woodlands (Cw) & - & 3 \\
\hline Cork oak woodlands (Co) & 4 & 10 \\
Other broadleaves woodlands (Bw) & 3 & - \\
\hline Inland waters (Iw) & - & 4 \\
Marine waters (Mw) & - & 4 \\
\hline Total & 14 & 41
\end{tabular}

LU/LC, land cover/land use; GCP, ground control points; Scr, Scrisi Mount; Ang, Angitola.

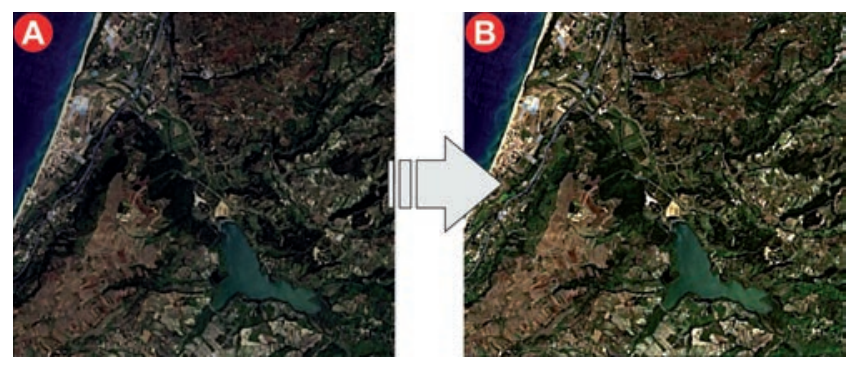

Figure 3. Example covering the Angitola (Ang) study area and showing the Landsat 8 image 10 August 2014 (path 188, row 33). A) The pan-sharpened at $15 \mathrm{~m}$ of spatial resolution; B) the same image after atmospheric and topographic corrections performed by means of the ATCOR3 algorithm. Both images are visualised in true colour (RGB 431 band combination). 
their number is three times greater for the Ang study area, due to its higher vegetation diversity compared to the Scr study area. According to other scholars (Arcidiacono and Porto, 2012; Arcidiacono et al., 2012) it depends on both class importance and variability of its information. Moreover, GCPs were utilised to obtain the spectral signatures of the defined LU/LC classes for the image classification. Spectral signatures from each class were collected and their area of interest (AOI) was used first to calculate the spectral separability of the cork oak woodlands and then as training set to perform the image classification.

The separability of the classes, based on the field analysis, was graphically analysed by comparison of histogram plot of the pixel values in the AOI signature of each OLI bands. Each individual histogram plot distribution curve was evaluated in order to verify if the signature may have two distinct classes of pixels and may need to be divided into two classes. Analysing the univariate statistics of each band of the AOI signature helped in making evaluations and comparisons. Moreover, the separability and consistency of the training sets can be evaluated by means of specific numeric indexes. In this work, Euclidean distance (ED) and divergence (D) were applied to measure spectral signatures separability and a contingency matrix (CM) was used to evaluate the consistency of the defined training sets. ED provides the spectral distance in a bi-dimensional spectral space between the mean vectors of each compared pair of signatures. If spectral distance is not significant, then they may not be distinct enough to produce a good classification. CM measures the percentage of the sample pixels that are actually classified as expected, classifying all of the pixels in the selected AOIs, and comparing the results with the pixels of a training sample. D measures the statistical distance between signatures and determines the band subsets that maximise the classification. GCP, coupled with other ancillary data, were selected as training samples to perform a supervised classification. In this stage of the study, a first classification was performed for both study areas for all the image datasets. A maximum likelihood classification (MLC) and minimum distance (MD) algorithms were applied in order to choose the best option for the areas under investigation. Using MLC requires the assumption that both the training data and the classes themselves display multivariate normal (Gaussian) frequency distributions (Lillesand et al., 2008; Campbell and Wynne, 2011). In order to reduce the salt and pepper effects, a fuzzy convolution algorithm, followed by a focal majority filter, was applied for both classification procedures (for both operations, a $3 \times 3$ pixels' kernel matrix was adopted). Prior to the satellite image interpretation, a classification method was designed for both study areas including the following 8 LU/LC classes: urban settlements (Ur); roads (Ro); crops
(Cr); coniferous woodlands (Cw); cork oak woodlands (Co); other broadleaves woodlands (Bw); inland waters (Iw); marine waters (Mw).

\section{Accuracy assessment}

In order to evaluate the user's and the producer's accuracy, a confusion matrix was applied to the classified images (Congalton, 1991; Congalton and Green, 2009). Four significant indexes metrics that express the accuracy in terms of omission/commission errors (i.e., pixels of the ground truth incorrectly classified) were derived: overall accuracy, user's accuracy, producer's accuracy, and the Kappa coefficient (K). To that purpose, a set of 30 randomly distributed sample points was defined in each of the two study areas.

\section{Results and discussion}

At the present stage of the research activity, suitable OLI images for the autumn and winter seasons are not available for the two investigated study-areas. This is due to several reasons: an excessive cloudiness covering the study areas; unavailability of scenes due to sensors anomalies in the first operational year and currently under reprocessing procedures. In the near future, as soon as relevant scenes will be made available, it will be interesting to explore also the autumn and winter conditions to better characterise the cork oak's spectral signature. The use of such images could avoid classification and on-screen interpreta-

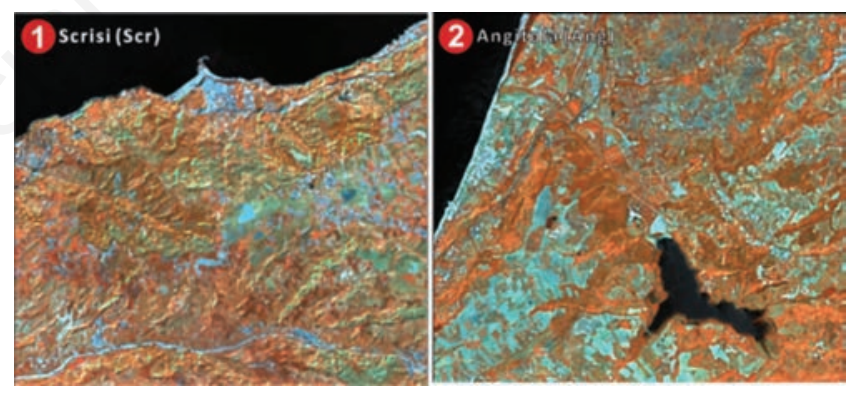

Figure 4. Example of the Landsat 8 image 23 April 2015 and 23 June 2014 (path 188, row 33) covering the two study-areas [1 - Scrisi Mount (Scr); 2 - Angitola (Ang)] shown in false colour emphasising the three infrared bands (RGB 567 band combination).
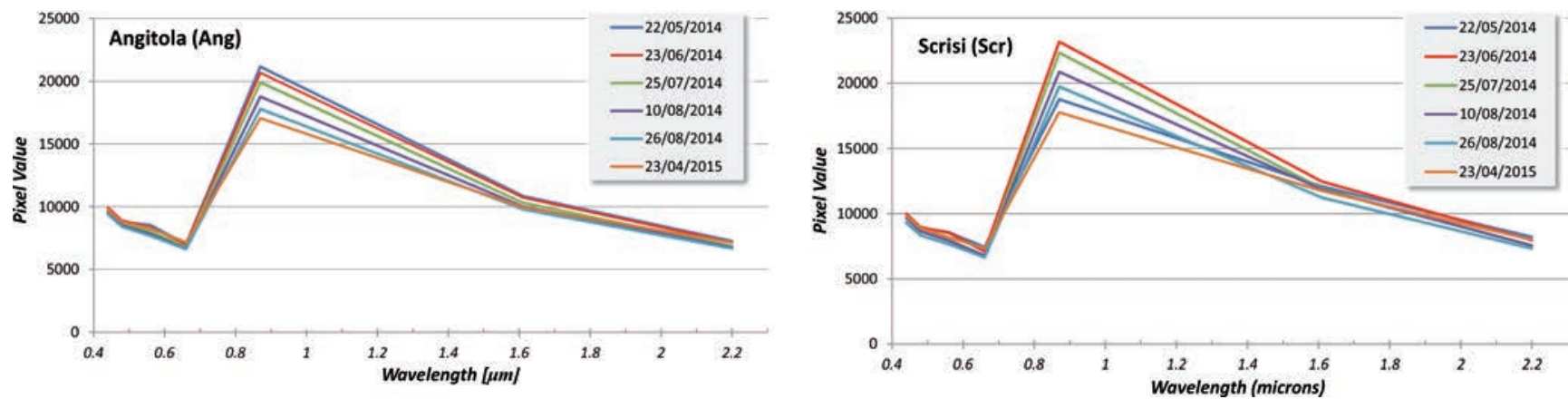

Figure 5. Comparison of typical spectral profiles of Cork oak woodlands in the two study-areas [Scrisi Mount (Scr) and Angitola (Ang)] and referring to the six Landsat 8 OLI images. 
tion problems (e.g., in the accuracy assessment stage) also reducing noise due to other broadleaves species. Moreover, the classification of cork oak forests can take advantage from the use of winter scenes thanks to the evergreen habitus of this species. Figure 4 shows the Landsat scene 23 April 2015 for the Scr study area and the scene 23 June 2014 for the Ang study area, highlighting the three infrared bands (5-7) that recorded the maximum reflectance for the cork oak woodlands. In all the examined periods, the analysis of the spectral profiles showed a higher reflectance in the infrared area, particularly in band 6 (Shortwave infrared, 1.57-1.65 m) (Figure 5). It can be noticed as the greatest number of pixel is distributed between band 5 and 6 (near infrared and shortwave infrared wavelength) (Table 3). As to the Scr study area, a better spectral separability was obtained for the image 22 May 2014; while, in the case of the Ang study area, better results were obtained for the image 26 August 2014. It means that, despite the geographical proximity of the two study areas, the different yearly rainfall amounts characterising them, which are higher in the Ang study area, had different effects on the phenology, and then on the reflectance val- ues and on the general behaviour of the cork oak's spectral signature, during the periods under investigation.

The results of the spectral separability analysis show that the highest values of spectral separability can be found on the image of 23 April 2015 for the Scr study area and of 23 June 2014 for the Ang study area. In particular, the values of spectral separability obtained comparing Co with $\mathrm{Cw}$ and $\mathrm{Bw}$ are worth mentioning. Actually, the latter two LU/LC classes are spectrally narrower than Co. Spectral discrimination between $\mathrm{Bw}$ and $\mathrm{Cw}$ was very successful, but this is not surprising, owing to the marked difference between these two groups in the nearinfrared reflectance region (Aardt et al., 2001) and despite the significant spectral variability recorded inside the Bw class. These results indicate the existence of inherent spectral differences (leaf-on) between the deciduous and coniferous species studied, confirming the spectral separability of these two groups at an operational level (Nelson et al., 1984; Frank, 1988; White et al., 1995). Spectral discrimination between $\mathrm{Co}_{0}$ and Bw proved less accurate but was still significant for both study areas. What emerges is a consistent confusion between $Q$.

Table 3. Univariate statistics of cork oak's area of interest spectral signature for each Landsat 8 operational land imager band that represent the average amount of spectral reflectance from oak trees in the scene (expressed in number of pixel per band).

\begin{tabular}{|c|c|c|c|c|c|c|c|c|}
\hline \multirow[b]{2}{*}{ Band } & \multicolumn{2}{|c|}{$\begin{array}{l}\text { Scrisi Mount } \\
23 \text { April 2015* }\end{array}$} & \multicolumn{2}{|c|}{$\begin{array}{l}\text { Scrisi Mount } \\
10 \text { August } 2014^{\circ}\end{array}$} & \multicolumn{2}{|c|}{$\begin{array}{l}\text { Angitola } \\
\text { 23 June 2014* }\end{array}$} & \multicolumn{2}{|c|}{$\begin{array}{c}\text { Angitola } \\
10 \text { August } 2014^{\circ}\end{array}$} \\
\hline & Mean & Std. dev. & Mean & Std. dev. & Mean & Std. dev. & Mean & Std. dev. \\
\hline 1 & 188.80 & 96.91 & 126.49 & 120.51 & 119.54 & 69.05 & 75.05 & 43.15 \\
\hline 2 & 190.31 & 88.59 & 127.67 & 110.99 & 125.08 & 60.25 & 80.79 & 36.90 \\
\hline 3 & 391.73 & 118.34 & 322.43 & 131.59 & 372.24 & 77.10 & 292.64 & 47.31 \\
\hline 4 & 306.92 & 107.70 & 221.15 & 133.29 & 212.079 & 56.31 & 162.35 & 36.02 \\
\hline 5 & 2763.85 & 444.89 & 2922.35 & 525.06 & 3248.12 & 326.13 & 3122.05 & 379.89 \\
\hline 6 & 1477.88 & 382.77 & 1544.65 & 393.06 & 1354.95 & 113.91 & 1267.98 & 110.22 \\
\hline 7 & 667.73 & 194.42 & 652.53 & 215.26 & 534.19 & 63.76 & 466.09 & 51.95 \\
\hline Total & 5987.2 & 1433.6 & 5917.3 & 1629.7 & 5966.2 & 766.5 & 5466.9 & 705.4 \\
\hline
\end{tabular}

Mean, mean value for the respective band; Std. dev., standard deviation value for the respective band. *Scene for which most accurate classifications were obtained; ${ }^{\circ}$ scene for which less accurate classifications were obtained.

Table 4. Synthesis of the spectral separability analysis performed for both study-areas, Scrisi Mount and Angitola.

\begin{tabular}{|c|c|c|c|c|c|}
\hline \multirow[t]{2}{*}{ Landsat 8 scene } & \multirow[t]{2}{*}{ LU/LC class pairs } & \multicolumn{2}{|c|}{ Euclidean distance } & \multicolumn{2}{|c|}{ Divergence } \\
\hline & & Scrisi Mount & Angitola & Scrisi Mount & Angitola \\
\hline \multirow{3}{*}{22 May 2014} & $\mathrm{Co}-\mathrm{Cr}$ & 1468 & 835 & 149 & 167 \\
\hline & $\mathrm{Co}-\mathrm{Cw}$ & - & 1027 & - & 107 \\
\hline & $\mathrm{Co}-\mathrm{Bw}$ & 2591 & 401 & 81 & 29 \\
\hline \multirow{3}{*}{23 June 2014} & $\mathrm{Co}-\mathrm{Cr}$ & 748 & 1347 & 51 & 308 \\
\hline & $\mathrm{Co}-\mathrm{Cw}$ & - & 884 & - & 104 \\
\hline & $\mathrm{Co}-\mathrm{Bw}$ & 1157 & 934 & 12 & 92 \\
\hline \multirow[t]{3}{*}{25 July 2014} & $\mathrm{Co}-\mathrm{Cr}$ & 732 & 1758 & 37 & 684 \\
\hline & $\mathrm{Co}-\mathrm{Cw}$ & - & 739 & - & 142 \\
\hline & $\mathrm{Co}-\mathrm{Bw}$ & 1500 & 989 & 11 & 133 \\
\hline \multirow[t]{3}{*}{10 August 2014} & $\mathrm{Co}-\mathrm{Cr}$ & 1266 & 1510 & 58 & 586 \\
\hline & $\mathrm{Co}-\mathrm{Cw}$ & - & 625 & - & 224 \\
\hline & $\mathrm{Co}-\mathrm{Bw}$ & 1266 & 591 & 11 & 140 \\
\hline \multirow[t]{3}{*}{26 August 2014} & $\mathrm{Co}-\mathrm{Cr}$ & 988 & 1721 & 90 & 141 \\
\hline & $\mathrm{Co}-\mathrm{Cw}$ & - & 1052 & - & 60 \\
\hline & $\mathrm{Co}-\mathrm{Bw}$ & 1186 & 1764 & 10 & 496 \\
\hline \multirow{3}{*}{23 April 2015} & $\mathrm{Co}-\mathrm{Cr}$ & 686 & 680 & 99 & 69 \\
\hline & $\mathrm{Co}-\mathrm{Cw}$ & - & 469 & - & 80 \\
\hline & $\mathrm{Co}-\mathrm{Bw}$ & 832 & 563 & 28 & 59 \\
\hline
\end{tabular}

LU/LC, land cover/land use; Cr, crops; Cw, coniferous woodlands; Co, cork oak woodlands; Bw, broadleaves woodlands. Higher values of Euclidean distance and lower values of divergence mean the best spectral LU/LC class separability. 
suber L. and $Q$. ilex L., which might have been expected since they belong to the same genus.

Moreover, considering that the three LU/LC classes are rather close to each other, a consistent number of training sets must be included in the analysis in order to perform a good image classification. With a view to better presenting the results obtained from the spectral separability analysis, those considered as more significant were summarised in Table 4.

The map accuracy of single-date Landsat classifications strongly depended upon the temporal sampling of each scene. Referring to the main objective of this research activity, i.e., to assess the potentiality of OLI sensor in mapping cork oak woodlands, the most accurate classifications were obtained on the images of 23 April 2015 and of 23 June 2014 for Scr and Ang, respectively (Tables 5 and 6). The overall $\mathrm{K}$ ranged from 0.87 to 0.95 and from 0.53 to 0.95 for Scr and Ang, respectively, revealing a good level of classification in the case of MLC and a non-satisfactory accuracy of MD classification. Applying MD algorithm, the highest overall accuracy was $63.3 \%$ for Scr and 60.0\% for Ang (overall K 0.12-0.50 for Scr, and 0.21-0.54 for Ang). These results are perfectly in line with what is largely accepted by scholars. In fact, MLC is a powerful classification technique, yet it should be considered that it is sensitive to variations in the quality of training data even more so than most other supervised techniques (Campbell and Wynne, 2011). The best overall classification accuracy achieved was over $85 \%$, a level universally considered as acceptable by practitioners (Congalton and Green, 2009). Moreover, it is within the range of overall accuracies achieved by using high-resolution airborne data in the classification of other highly heterogeneous landscapes in Mediterranean climate zones (Coulter et al., 2000; Koetz et al., 2008; Sluiter and Pebesma, 2010). It should also be noted that the classification accuracy values obtained were also based on reference data that, whilst as accurate as possible, may themselves attribute erroneous labels to validation sites and cannot be completely relied upon as ground truth (Congalton and Green, 2009). The good discrimination of cork oak can be explained by late spring-summer peak differences from the other tree species and the shrub layer. In fact, at this time of the year, the understorey has a very light colour, which is due to the presence of dry vegetation and soil. The tree canopy of cork oak is darker and when tree canopy cover increases, the reflectance of the pixel unit (MS band 4-Red) decreases, because the soil reflects solar radiation and the chlorophyll absorbs it.

The same situation can be noticed in the MIR, but the absorption is due to the presence of water in the living tissues. In the NIR (MS band 5), crowns are highly reflective, as well as the understorey of bright soils and dry grass, such as in the Scr and Ang study areas. Satellite imagery acquired in the late summer maximises the spectral contrast between the evergreen tree crowns and the dry herbaceous background. However, the study areas are still characterised by an extremely variable understorey. According to Huete (1989), areas with significant soil brightness, changes arising from moisture differences, roughness variations, shadow, or organic-matter differences, show soilinduced influences on the vegetation indices values. These effects are predominant in partially vegetated canopies.

Table 5. Scrisi Mount study-area. Accuracy assessment (\%) at pixel level for both the classification methods used and referring to the whole classified L8 imagery dataset.

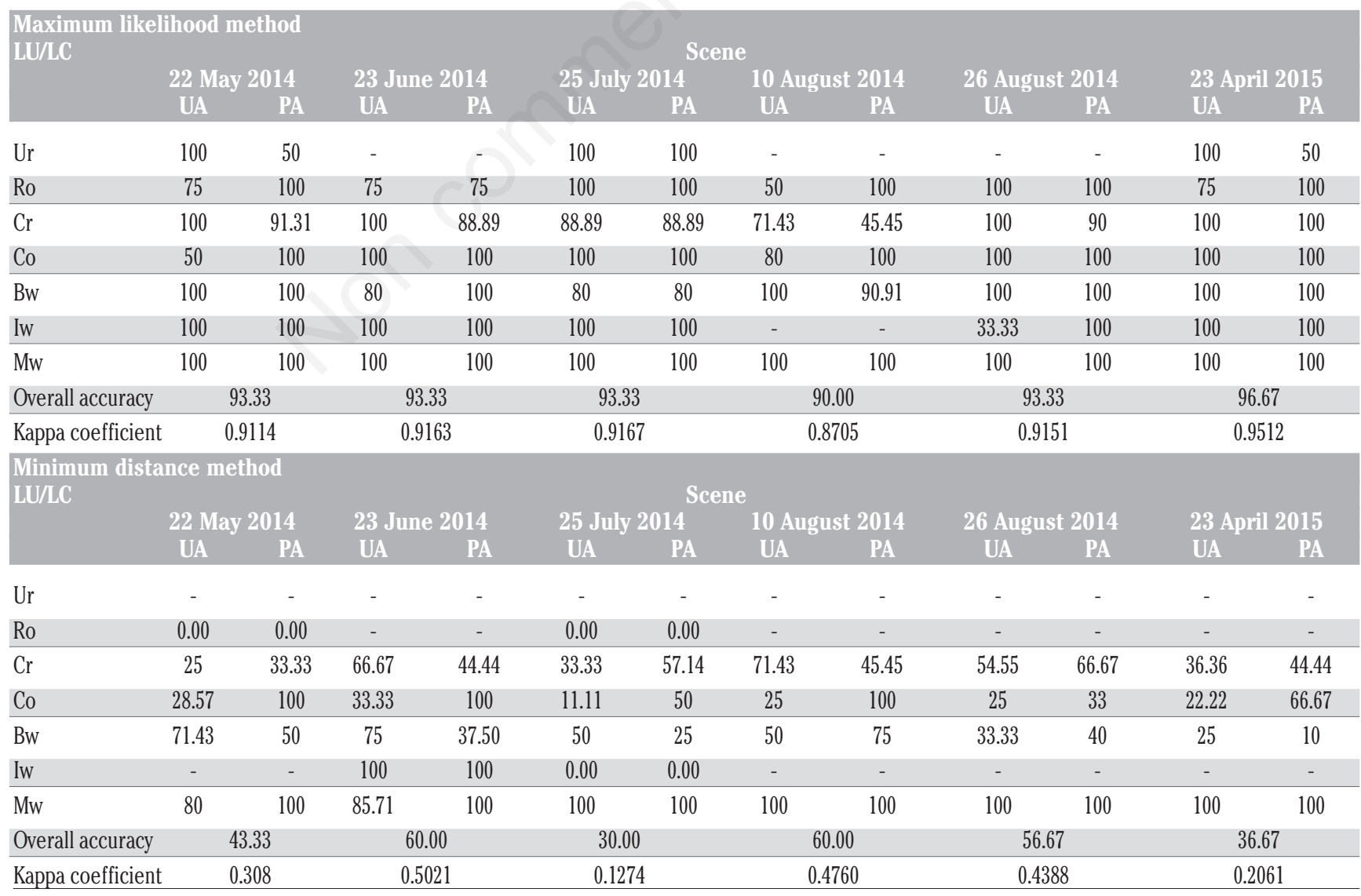

LU/LC, land cover/land use; UA, user's accuracy; PA, producer's accuracy; Ur, urban settlements; Ro, roads; Cr, crops; Co, cork oak woodlands; Bw, broadleaves woodlands; Iw, inland waters; Mw, marine waters. 
Always referring to the goal of this paper, the analysis of the best image classification obtained for Scr (23 April 2015) and Ang (23 June 2014) showed that the detected cork oak woodlands occupy an area of 453 ha for the Scr and 291 ha for the Ang study area (9\% and 6\% of the examined scene, respectively) (Figure 6). As to the classification accuracy, Co was detected with an accuracy of $100 \%$ [for both User's and Producer's accuracies (UA and PA)] in the Scr study area, while 100\% UA and 75\% PA were obtained in the Ang study area. Figure 7 shows the land distribution according to LU/LC classes among the L8 images with the best and the worst overall accuracy obtained.

The Landsat 8 OLI panchromatic band has a band-pass narrower than the one of previous Landsat sensors (Roy et al., 2014) and this results in images presenting greater contrast between vegetated and bare surfaces, thus enhancing classification training and validation data collection. Findings suggest that Landsat 8 imagery can successfully support an overall accurate detection of cork oak woodlands. Despite the limitation of spatial resolution, Landsat products are usually used to map vegetation at community level (Xie et al., 2008). It is a challenging task to use Landsat 8 images for mapping at species level, especially in a heterogeneous environment like the Calabria region.

This study suggested that, when these images integrate with other ancillary data, it becomes possible to map species as well as to carry out other studies (Doma and Süzen, 2006) to produce regional scale vegetation maps with a high overall accuracy. Moreover, ancillary data, including field samples, topographical features, environmental characteristics and other spatial data layers, seems to be very helpful to get a more satisfactory result and increase classification accuracy (Xie et al., 2008). However, this is not always true, especially in cases like those presented in this paper in which a study area is covered with vegetation of complex forms that, at different seasonal stages, either present similar spectral responses between different vegetation groups or generate spectral variations for the same vegetation group (Sha et al., 2008). This might have been an important factor, since the effect of the sensor spatial resolution is directly related to the spatial heterogeneity of the remotely sensed area (Marceau et al., 1994). However, that confirms the challenge to use Landsat family images because they provide the fine-grained data necessary for detecting the high level of spatial heterogeneity expected in the Mediterranean environments (Fernández et al., 2010).

All examples corresponding to the categories Mw and Iw were classified correctly (100\% for both UA and PA for each study area). As highlighted by Rodriguez-Galiano et al. (2012), the most difficult categories to classify are those with high intra-class variability, such as urban settlements and, with reference to this study, woodlands. When mapping vegetation under such circumstances, various difficulties are often encountered, hence it could be better to adopt more advanced image classification methods, such as sub-pixel analysis (Lee and Lathrop, 2005). Another solution could be to choose higher resolutions of imagery so as to increase distinguishability in image classification. However, higher resolutions of imagery will most likely increase the cost.

Table 6. Angitola study-area. Accuracy assessment (\%) at pixel level for both classification methods and referring to the whole classified L8 imagery dataset.

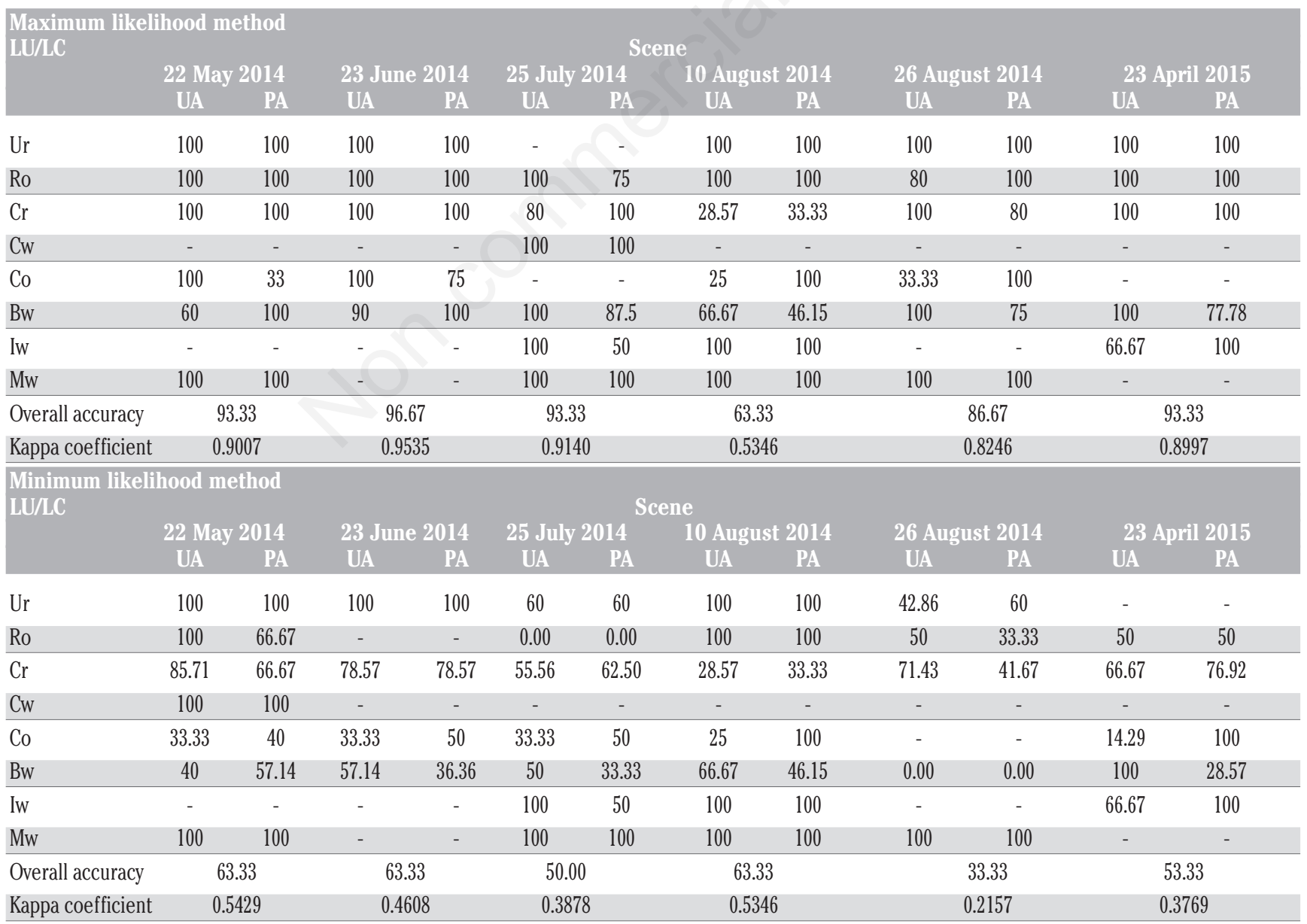

LU/LC, land cover/land use; UA, user's accuracy; PA, producer's accuracy; Ur, urban settlements; Ro, roads; Cr, crops; Cw, coniferous woodland; Co, cork oak woodlands; Bw, broadleaves woodlands; Iw, inland waters; Mw, marine waters. 

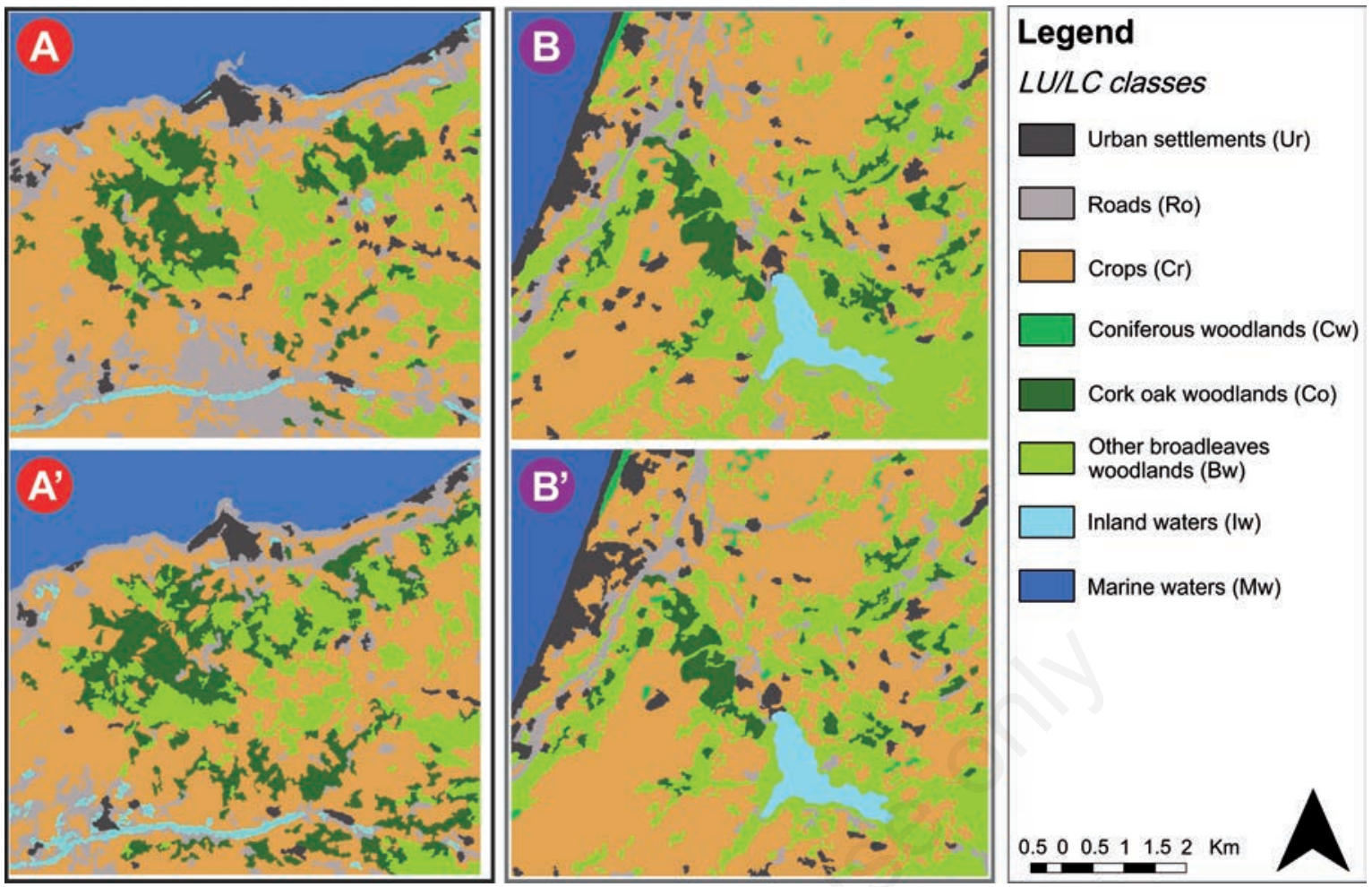

Figure 6. The best (A, B) and the worst (A', B') results obtained in detecting cork oak woodlands are shown for the two study-areas [A, Scrisi Mount (Scr) - B, Angitola (Ang)]. All classified images are produced applying the maximum likelihood classification algorithm followed by fuzzy convolution and a focal majority filter. LU/LC, land cover/land use.
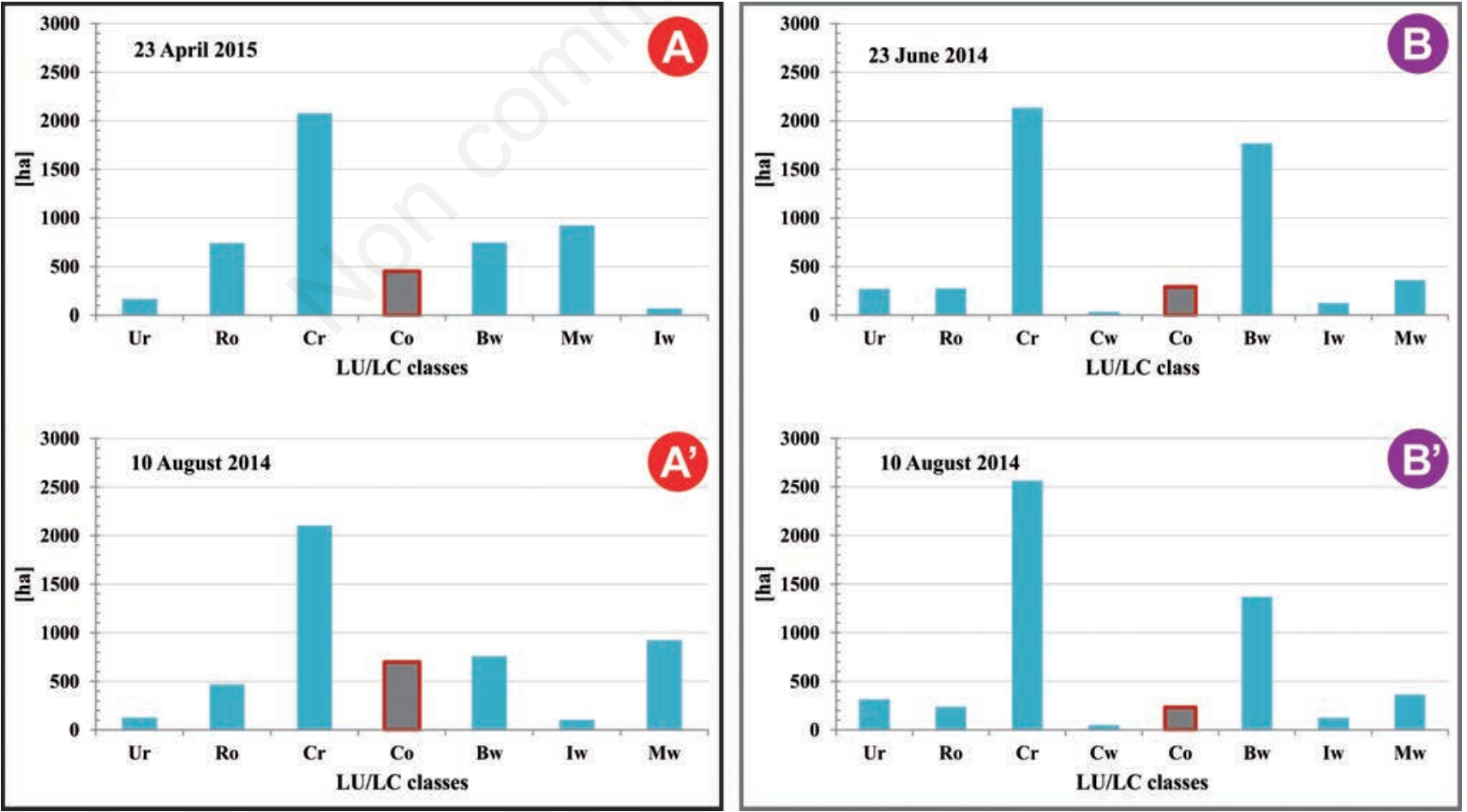

Figure 7. Land distribution according to land cover/land use (LU/LC) classes referring to the best (A, B) and the worst (A', B') image classification used for detecting of cork oak woodlands [A, Scrisi Mount (Scr) - B, Angitola (Ang)]. 


\section{Conclusions}

In this first step of the research activity, a set of multi-temporal Landsat OLI imagery for years 2014 and 2015 was implemented in order to assess the potential performance of this new sensor in detecting the presence of cork oak woodlands. Particular attention was paid to the evaluation of the spectral separability of cork oak woodlands in 1-7 MS OLI bands on atmospheric and topographic corrected images. To this end, ED and D indexes were applied in order to quantitatively measure spectral signature separability, while the consistency of the defined training sets was assessed by means of $\mathrm{CM}$.

As it could be expected, at medium and small spatial scales (1:50,000 or smaller), OLI sensor provides good results thanks to its improved spectral resolution depth compared to the previous Landsat family sensors. Moreover, the main advantage, which determined its choice in this research activity, can be found in the free availability coupled with a high revisitation period (theoretically, Landsat 8 , in conjunction with Landsat ETM+, can reach a revisitation period of 8 days).

To better investigate the spectral separability of cork oak woodlands, a more complete group of training sets, including eight LU/LC, was defined. Therefore, an exemplificative supervised classification for both study areas was included in this paper.

Finally, one of the recognised challenges in mapping cork oak population is that the species' spectral response is quite similar to that of $Q$. ilex $\mathrm{L}$., a widespread species in the Mediterranean basin that is often found near or mixed to $Q$. suber L., as well as to that of olive groves (Olea Europea L.). To this end, future research direction will deal with the analysis of satellite images with different geometric and spectral characteristics (i.e., WorldView- 2 and 3 , and the MS data from the Sentinel-2 mission launched on 23 June 2015 in the framework of the Europe's global environmental monitoring programme Copernicus (www.esa.int/Our_Activities/Observing_the_Earth/Copernicus Accessed: 26 May, 2016).

\section{References}

Aardt J.a.N. Van, Wynne R.H., Oderwald R.G., Campbell J.B. 2001. Spectral separability among six southern tree species. Photogramm. Eng. Remote Sensing 67:1-184.

APCOR. 2015. APCOR's Cork Yearbook 2015. Portuguese Cork Association, Santa Maria de Lamas, Portugal.

Arcidiacono C., Porto S.M.C. 2012. Pixel-based classification of highresolution satellite images for crop-shelter coverage recognition. Acta Hortic. 937:1003-10.

Arcidiacono C., Porto S.M.C., Cascone G. 2012. Accuracy of crop-shelter thematic maps: A case study of maps obtained by spectral and textural classification of high-resolution satellite images. J. Food. Agric. Environ. 10:1071-4.

Aronson J., Pereira J.S., Pausas J.G. 2009. Introduction. In: J. Aronson, J.S. Pereira, J.G. Pausas (Eds.), Cork oak woodlands on the edge: conservation, adaptive management, and restoration. Island Press, Washington, DC, USA, 1-6.

Balthazar V., Vanacker V., Lambin E.F. 2012. Evaluation and parameterization of ATCOR3 topographic correction method for forest cover mapping in mountain areas. Int. J. Appl. Earth Obs. Geoinf. 18:43650.

Bugalho M.N., Caldeira M.C., Pereira J.S., Aronson J., Pausas J.G. 2011. Mediterranean cork oak savannas require human use to sustain biodiversity and ecosystem services. Front. Ecol. Environ. 9:278-86.

Campbell J.B., Wynne R.H. 2011. Introduction to Remote Sensing. The
Guilford Press, New York, NY, USA.

Carreiras J.M.B., Pereira J.M.C., Pereira J.S. 2006. Estimation of tree canopy cover in evergreen oak woodlands using remote sensing. For. Ecol. Manage. 223:45-53.

Catry F.X., Moreira F., Cardillo E., Pausas J.G. 2012a. Post-fire management of cork oak forests. In: F. Moreira, M. Arianoutsou, P. Corona, J. De las Heras (Eds.), Post-fire management and restoration of southern European forests. Springer, Dordrecht, Netherlands, p. 329.

Catry F.X., Moreira F., Pausas J.G., Fernandes P.M., Rego F., Cardillo E., Curt T. 2012b. Cork oak vulnerability to fire: the role of bark harvesting, tree characteristics and abiotic factors. PLoS 0ne 7:1-9.

Congalton R.G. 1991. A review of assessing the accuracy of classifications of remotely sensed data. Remote Sens. Environ. 37:35-46.

Congalton R.G., Green K. 2009. Assessing the accuracy of remotely sensed data: Principles and practices. CRC Press Taylor \& Francis Group, Boca Raton, FL, USA.

Coulter L., Stow D., Hope A., Leary J.0., Turner D., Longmire P., Peterson S., Kaiser J. 2000. Comparison of high spatial resolution imagery for efficient generation of GIs vegetation layers. Photogramm. Eng. Remote Sens. 66:1329-35.

Dahiya S., Garg P.K., Jat M.K. 2013. A comparative study of various pixel-based image fusion techniques as applied to an urban environment. Int. J. Image Data Fusion 4:197-213.

Doma A., Süzen M.L. 2006. Integration of environmental variables with satellite images in regional scale vegetation classification. Int. J. Remote Sens. 27:1329-50.

Di Palma F., Amato F., Nolè G., Martellozzo F., Murgante B. 2016. A SMAP Supervised Classification of Landsat Images for Urban Sprawl Evaluation. ISPRS Int. J. Geo-Inf. 5:109.

European Commission. 1992. Council Directive 92/43/EEC of 21 May 1992 on the conservation of natural habitats and of wild fauna and flora. In: Official Journal L 206, 22/07/1992, pp 7-50.

FAO (Food and Agriculture Organisation of the United Nations). 2013. State of Mediterranean forests 2013. FAO, Rome, Italy.

Fernández N., Paruelo J.M., Delibes M. 2010. Ecosystem functioning of protected and altered Mediterranean environments: a remote sensing classification in Doñana, Spain. Remote Sens. Environ. 114:211-20.

Fichera C.R., Laudari L., Modica G. 2015. Application, validation and comparison in different geographical contexts of an integrated model for the design of ecological networks. J. Agric. Engine. 46:52-61.

Fichera C.R., Modica G., Pollino M. 2011. GIS and remote sensing to study urban-rural transformation during a fifty-year period. In: B. Murgante, 0. Gervasi, A. Iglesias, D. Taniar, B.O. Apduhan (Eds.), Computational science and its applications - ICCSA 2011, Part I, Lecture Notes in Computer Science. Springer, Heidelberg, Germany, pp 237-252.

Fichera C.R., Modica G., Pollino M. 2012. Land Cover classification and change-detection analysis using multi-temporal remote sensed imagery and landscape metrics. Eur. J. Remote Sens. 45:1-18.

Frank T.D. 1988. Mapping dominant vegetation communities in the Colorado Rocky Mountain front range with landsat thematic mapper and digital terrain data. Photogramm. Eng. Remote Sens. 54:1727-34.

Godinho S., Gil A., Guiomar N., Neves N., Pinto-Correia T. 2014. A remote sensing-based approach to estimating montado canopy density using the FCD model: a contribution to identifying HNV farmlands in southern Portugal. Agrofor. Syst. 90:23-34.

Goodenough D.G., Deguise J., Robson M.A. 1990. Multiple expert systems for using digital terrain models. pp 961-961 in 10th Annual International Symposium on Geoscience and Remote Sensing, Symposium - IGARSS '90 IEEE, New York, NY, USA. 
Huete A.R. 1989. Soil influences in remotely sensed vegetation-canopy spectra. In: G. Asrar, (Ed.), Theory and applications of optical remote sensing. Wiley Interscience, New York, NY, USA, pp 107141.

Irons J.R., Dwyer J.L., Barsi J.A. 2012. The next Landsat satellite: the Landsat data continuity mission. Remote Sens. Environ. 122:11-21.

Ke Y., Im J., Lee J., Gong H., Ryu Y. 2015. Characteristics of Landsat 8 OLI-derived NDVI by comparison with multiple satellite sensors and in-situ observations. Remote Sens. Environ. 164:298-313.

Koetz B., Morsdorf F., van der Linden S., Curt T., Allgöwer B. 2008. Multi-source land cover classification for forest fire management based on imaging spectrometry and LiDAR data. For. Ecol. Manage. 256:263-71.

Lee S., Lathrop R.G. 2005. Sub-pixel estimation of urban land cover components with linear mixture model analysis and Landsat Thematic Mapper imagery. Int. J. Remote Sens. 26:4885-905.

Lillesand T.M., Kiefer R.W., Chipman J.W. 2008. Remote sensing and image interpretation. 6th ed. Hoboken, NJ: John Wiley \& Sons.

Liu JG. 2000. Smoothing filter-based intensity modulation: a spectral preserve image fusion technique for improving spatial details. Int. J. Remote Sens. 21:3461-72.

Marceau D.J., Gratton D.J., Fournier R.A., Fortin J.P. 1994. Remote sensing and the measurement of geographical entities in a forested environment. 2.The optimal spatial resolution. Remote Sens. Environ. 49:105-17.

Modica G., Merlino A., Solano F., Mercurio R. 2015. An index for the assessment of degraded Mediterranean forest ecosystems. For. Syst. 24:e037:13.

Modica G., Vizzari M., Pollino M., Fichera C.R., Zoccali P., Di Fazio S. 2012. Spatio-temporal analysis of the urban-rural gradient structure: an application in a Mediterranean mountainous landscape (Serra San Bruno, Italy). Earth Syst. Dynam. 3:263-79.

Nelson R.F., Latty R.S., Mott G. 1984. Classifying northern forests using thematic mapper simulator data (Maine). Photogramm. Eng. Remote Sens. 50:607-17.

Padwick C., Deskevich M., Pacifici F., Smallwood S. 2010. Worldview-2 pan-sharpening. pp. 14 in ASPRS 2010 Annual Conference, San Diego, CA, USA.

Pausas J.G., Pereira J.S., Aronson J. 2009. The tree. In: J. Aronson, J.S. Pereira, J.G. Pausas (Eds.), Cork oak woodlands on the edge: conservation, adaptive management, and restoration. Island Press, Washington, DC, USA, pp. 11-21.

Richter R. 1997. Correction of atmospheric and topographic effects for high spatial resolution satellite imagery. Int. J. Remote Sens. 18:1099-111.

Richter R. 1998. Correction of satellite imagery over mountainous terrain. Appl. Opt. 37:4004.

Richter R. 2008. Haze reduction, atmospheric and topographic correction. ATCOR2 and ATCOR3 User Manual. Germering, Germany.

Richter R., Kellenberger T., Kaufmann H. 2009. Comparison of topographic correction methods. Remote Sens. 1:184-96.

Rodriguez-Galiano V.F., Ghimire B., Rogan J., Chica-Olmo M., RigolSanchez J.P. 2012. An assessment of the effectiveness of a random forest classifier for land-cover classification. ISPRS J. Photogramm. Remote Sens. 67:93-104.

Rogan J., Miller J. 2006. Integrating GIS and remotely sensed data for mapping forest disturbance and change. In: M.A. Wulder and S.E. (Eds.), Franklin Understanding forest disturbance and spatial pattern: remote sensing and GIS approaches. CRC Press Taylor \& Francis Group, Boca raton, FL, USA, pp. 133-172.

Rossi L., Borfecchia F., De Cecco L., Martini S., Natali S., Mantovani S. 2009. Ricognizione delle aree a sughereta nella Regione Lazio tramite immagini IKONOS e LANDSAT. pp. 1685-1689 in Proc. 13th Conference ASITA (Italian Federation of the Scientific Associations for the Environmental and Territorial Informations), Bari, Italy [in Italian].

Roy D.P., Wulder M.A., Loveland T.R., Allen R.G., Anderson M.C., Helder D., Irons J.R., Johnson D.M., Kennedy R., Scambos T.A., Schaaf CB., Schott J.R., Sheng Y., Vermote E.F., Belward A.S., Bindschadler R., Cohen W.B., Gao F., Hipple J.D., Hostert P., Huntington J., Justice C.0., Kilic A., Kovalskyy V., Lee Z.P., Lymburner L., Masek J.G., McCorkel J., Shuai Y., Trezza R., Vogelmann J., Wynne R.H., Zhu, Z. 2014. Landsat-8: Science and product vision for terrestrial global change research. Remote Sens. Environ. 145:154-72.

Sha Z., Bai Y., Xie Y., Yu M., Zhang L. 2008. Using a hybrid fuzzy classifier (HFC) to map typical grassland vegetation in Xilin River Basin, Inner Mongolia, China. Int. J. Remote Sens. 29:2317-37.

Signorello P. 1984. Osservazioni fitosociologiche su alcuni aspetti boschivi dei Quercetea ilicis dell'Italia meridionale. Not. Fitosociol. 19:177-82 [in Italian].

Sluiter R., Pebesma E.J. 2010. Comparing techniques for vegetation classification using multi- and hyperspectral images and ancillary environmental data. Int. J. Remote Sens. 31:6143-61.

Vanonckelen S., Lhermitte S. 2014. Performance of atmospheric and topographic correction methods on Landsat imagery in mountain areas. Int. J. Remote Sens. 35:4952-72.

Vessella F., Schirone B. 2013. Predicting potential distribution of Quercus suber in Italy based on ecological niche models: conservation insights and reforestation involvements. For. Ecol. Manage. 304:150-61.

Wang C., Lu Z., Haithcoat T.L. 2007. Using Landsat images to detect oak decline in the Mark Twain National Forest, Ozark Highlands. For. Ecol. Manage. 240:70-8.

White J.D., Kroh G.C., Pinder J.E. 1995. Forest mapping at Lassen Volcanic National Park, California, using Landsat TM data and a geographical information system. Photogramm. Eng. Remote Sensing 61:299-305.

WWF MedPO 2006. Cork screwed? Environmental and economic impacts of the cork stoppers market. WWF, Rome, Italy.

Xie Y., Sha Z., Yu M. 2008. Remote sensing imagery in vegetation mapping: a review. J. Plant Ecol. 1:9-23.

Zhu X., Liu D. 2014. Accurate mapping of forest types using dense seasonal landsat time-series. ISPRS J. Photogramm. Remote Sens. 96:1-11. 